The Geneva Papers on Risk and Insurance, 20 (No. 76, July 1995) 374-392

\title{
Environment and Insurability The Application of Risk Management Principles to Running an Insurance Company*
}

\author{
by John D. Arpel**
}

\section{Introduction}

The latest theories are pushing stock companies to create "Economic Value Added", or what McKinsey calls "Stakeholder Value". If you can earn $9 \%$ on a long term government bond, you will need at least a $25 \%$ return on a risky investment like insuring environmental pollution. Pressures on managements to deliver high returns will also conflict with continuity. The words "environment" and "insurability" are not compatible.

The concept of "ensurance" and "ensurability" is presented and developed as a compatible theory for the solution of environmental cover problems.

We can recognize that some insurance managements have acted like the captain and the engineers of the Titanic, placing too much faith in the infallibility of the systems they and their predecessors have developed. This has led to disasters like the mortgage indemnity guarantee business, and spiral covers costing millions of pounds sterling. We need someone in the organisation to remind us - "What if?".

This paper proposes the integration of risk management principles in the running of insurance companies. into:

It starts with risk evaluation, and moves on to risk identification, breaking this down

Human exposures,

Material exposures,

Procedural exposures,

Legal exposures,

Image exposures,

Economic and Political exposures.

* Paper presented at the MORE 10 - Seminar in Courbevoie, France, November 1994. It is part of a study done for the Chartered Insurance Institute, London.

** Reinsurance Division, Elvia Insurance Company, Zurich. 


\section{Environment and insurability}

Insurance Companies must survive in the business environment, and one of the current "sexy" terms in the business environment is "Economic Value Added" or EVA for short. EVA focuses on what really matters to investors - the cash they earn on their capital.

McKinsey favours a refinement it calls "Stakeholder Value". This states that a company only creates economic value if it returns market rates to all stakeholders in the business, including labour, management and investors.

In current market conditions investors can secure some $9 \%$ return on a long-term government bond. The stock market in general, which represents a greater risk, demands a risk premium some $6 \%$ higher. Thus the average cost of equity capital is currently about $15 \%$.

If shareholders risk losing their shirts, and Lloyd's is currently an example where some investors are doing just that, there is a so-called beta factor allocated to reflect the increased level of risk such organisations may carry.

It is therefore not unreasonable when talking of insuring environmental liability that investors or stakeholders would require a return on their investment of between 20 and $25 \% \ldots$ and this type of insurance is likely to be very capital hungry.

Please also note a recent quote: "A business exists to make money for its owners, not for any sociological reasons".

In fact, when one is talking with his insurance partners, if they are stock companies, the above is the reality of their environment.

When we are discussing the environment, we have become the childrens' children. Our fathers' fathers extracted wealth and profit for their generations without considering what we may term the natural environment, and today we must use a part of our wealth to resolve past problems, and take account of these problems when creating new wealth.

Is there a compatibility between Insurance and the Environment?

On the one hand many of today's insurance companies will have unknown exposures to past environmental damage. These exposures could probably exceed the entire asset base of the industry if developed to their full potential, hence the need in the United States to revise the "Superfund" concepts and create reasonable parameters, sharing the liabilities of the past between various sectors of society. There are also exposures such as tobacco smoke which have not yet developed to their full potential, and represent another possible drains on the assets of the Insurance Industry.

This is not to spread doom and gloom. But it is one thing to pay smaller premiums to protect short term risks such as Property perils, or the shorter term casualty perils, and it is quite another to deposit considerable sums over a long period for exposures that will in many cases be inevitable.

Would there anyway be the exposure to using today's premiums to pay yesterday's losses? Also with the financial objectives of a $20-25 \%$ return on capital, could a buyer rely on any part of the industry to commit itself long term? 
I better clearly state that I am wholly committed to the Insurance and Reinsurance Industry, and I am not suggesting to look elsewhere for a buyer to solve customers' problems, but in finding the solutions you must understand the business environment in which Insurers must survive today, and you must develop a concept that fulfils each parties' requirements.

For this reason I am going to drag up from the past - March 1986 to be precise - a concept I started to develop in an article to cover Municipal liabilities, which I termed "Ensurance".

If we can all agree that Insurance is not a charitable institution, then logically environmental exposures must be covered using the resources of those who have the exposures. However we are not talking here about the losses of the few being covered by the premiums of the many. We are not talking about a mutualisation of many small risks, and a few large claims. We are talking about specific industry sectors, usually large clients, sometimes with assets vastly exceeding those of the insurer. We are talking about potentially massive, even catastrophic claims which may never be repaid by the particular insured, and which could not be borne by the many because there is no large group of insureds. I thus challenge their INsurability, though not of course their ENsurability!

If I state, quite reasonably, that this must be a self-funding exercise, then one might ask why bother discussing the issue with Insurers. All we need are our industry experts and our risk managers.

One of the motivating factors behind this paper is to encourage two very close family members, the Insurer and the Risk Manager to weld all their good ideas together for the increased benefit to both parties. There will be no better combination of talent, with the specific academic and business interests, to solve the environmental problems that we face today.

Business environmentalists need the expertise, the wealth of statistical, legal and local knowledge of insurers and risk managers, and their administrative abilities to gauge, structure and price risks, and to adjust claims. However while the insurance and reinsurance industry can certainly be involved for certain layers of exposures, the cost of using their capital extensively will be too expensive, and their long term capital commitment too uncertain.

Also the full cover required is likely to be commercially unobtainable, or only obtainable with highly uncertain long term security. There is simply no magic!

Finally, if we want to "Ensure" an environmentally satisfactory future, we need to obtain the commitment of society through its duly elected representatives. This raises problems when we start to talk about global commitment, as societies which lack forms of government prepared to contribute to this objective not only hamper this "Ensurance", but may also contribute to substantial further pollution.

However there are evidently exposures too great for the insurance industry to handle correctly, and it would be quite stupid for the industry to risk its services to many other sectors of society by thinking it can cover such risks. 


\section{The application of risk management principles to running an insurance company}

Directors and Officers have some legal obligations towards the shareholders and the companies they manage. One of the most important of these is to look after the company's assets. Another important objective is to give a reasonable return to shareholders.

Risk management is the systematic economic control of threats against a corporation's assets and earnings.

One could thus argue that Directors and Officers have a legal obligation to apply risk management principles in any company.

Many directors and employees of Insurance Companies would confirm that they are already doing their utmost both to protect the company's assets, and to give a reasonable return to shareholders. So why bother to waste time additionally by employing a risk manager.

Every one has read something new about the sinking of the Titanic, and one can imagine some of the very experienced captains of our own industry standing on the bridge of the Titanic on that fateful day.

Just like the marine experience of many years had produced a technically unsinkable ship, so decades of insurance management techniques had produced an industry which could survive any eventuality.

It was only two hours after striking the iceberg that the captain ordered the first SOS sending, and it took the Carpathia some two hours from this moment to arrive on the scene, about one hour and forty-five minutes too late.

Apart from the major mistake in believing in the infallibility of the technical system, there was also very poor communication - it took some fifty minutes for the third officer to be informed of the situation and the crew did not even know that the ship had been installed with life boats that could be launched full. Thus only 711 passengers eventually found a place, where there was capacity for 1,178 .

A final little point to make here is that the law stated that for ships of more than 15,000 tons a minimum of 16 lifeboats were necessary. This gave a capacity, as mentioned, of 1,178 persons. There were 2,207 lives aboard the Titanic. Nobody had questioned the need to go beyond the letter of the law.

Would the situation have been different if there had been someonc available who ignored the best marine experience of the time, and the latest marine techniques, and just asked some plain common sense questions - like what if the ship should sink?

The fact that several Insurance Companies both wrote significant Mortgage Indemnity business, and invested in the property market, begs a similar question.

When the consequences of our actions can result in the loss of hundreds of lives, or millions of pounds, should we not ask if apart from our legal obligations, there may be real profit to have someone around who is authorised to question our infalliblc logic, and attempt, ever so nicely, to place some perspective on our ego?

In our own advertising as an industry, we ourselves recommend risk management to our clients and distinguish between the "pure" and the "speculative" risks. It thus seems quite legitimate to expand this concept also to the running of an insurance company. 


\section{Evaluating risk}

There are a number of theories of risk assessment, and in addressing a fraternity of largely insurance specialists, it is not necessary to enlarge on the more classical theories in common use in the profession.

Clearly risk assessment in our business remains largely based on the parameters of "frequency" and "severity", ie how often is " $x$ " going to occur, and how much is " $x$ " going to cost?

However, I must say that I would be very reluctant to fly in an aitcraft which has been built based on such essentially historical assessments of risk such as if Joe's last aircraft worked $\mathrm{OK}$, there is a good chance his new one will too!

It is thus interesting to consider certain other concepts, and to review how they might apply in the environment of an insurance company.

Research engineers for example must adjudge the dependability of their product. How do they break down this process?

One method breaks down this subject into four main areas:

- Reliability: The aptitude to function without a breakdown.

- Availability: The aptitude to be in a functional state.

- Maintainability: The aptitude for repair after a breakdown.

- Security: The aptitude not to cause a catastrophe to humans, or the environment.

I do not intend to go into the detail of this method of risk assessment, nor to elaborate on the other methods in my paper, I merely wish to emphasise that many alternative methods used, ignore or place little value on what may have happened in the past in possibly similar situations, and view risk today based on today's concepts, and what "is" today.

Not too long ago certain syndicates in Lloyd's took twenty claim free years as a good reason to enter the catastrophe market. However part of the loss situation that resulted may have been a failure to really test the ideas and systems they wished to employ in writing such business in the then current environment.

With technology moving at such a pace today, will we ever have homogenous data in a large number of fields that is consistent enough over a period of time, for us to make any valid projections from it?

A number of risk managers seem to have gone beyond purely classical methods of assessing risk, and also given the advantage of having in-house expertise at their disposal, they have evolved various methods of assessing and dealing with risk. Should we not as Insurers and Reinsurers be open to all ideas that could improve the service we want to give to our clients, and to achieve the returns our shareholders expect from us?

Moving on from techniques of risk assessment, it is interesting to try to identify the risks that exist in an insurance company.

\section{Human exposures}

\subsection{Inside the company}

a) Recruitment

Ultimately, recruitment is one of the most essential areas where a number of exposures can be reduced. Careful recruitment into the different job categories can enhance motiva- 
tion, reduce medical care bills, reduce errors and generally contribute to the efficiency of the organisation.

The recruitment parameters can be designed to include certain levels of psychological testing, handwriting analysis, health checks, and various other measures contributing to efficiency and safety.

A good example of unfortunate recruitment practices might have been the hiring of an Underwriter to write business in the London Market as viewed by a "foreign" employer. A desirable candidate might be one that has had good experience with one of the traditional UK companies writing the class or classes of business sought by the new employer. Also perhaps an educational background of a degree and an FCII. An added benefit would be a pleasant and industrious individual, well connected with the market.

However what interviews may have failed to reveal was the strength of character necessary to face up to the often significant pressure exerted by the broker in face-to-face underwriting situations. While the individual knew what should and should not be written, he/she simply could not say "no"... enough.

Careful consideration of such exposures would help to refine the recruitment process.

The opposite side of the coin, "easing the exit", should also be given careful consideration. The trend towards lawsuits in such circumstances, or large "redundancy" packages can sometimes outweigh any potential cost savings associated with cutbacks, or other measures.

In addition large scale redundancies can cause gaps in the age and skill/experience ranges if such actions are not very carefully planned. This can lead to significant bottlenecks in decision making as limits at one level are quickly exceeded, and experience at the next level is inadequate or lacking.

b) First Aid

How many offices seriously encourage attendance at First Aid courses?

How many offices provide employees with gloves to handle situations where bleeding could occur, or other interventions, giving rise to diseases including the currently well publicised AIDS?

Training should include a variety of situations, including the blowing out of windows caused by a bomb blast, and heart attacks.

c) Fidelity

Fidelity is an exposure with a very wide range of possibilities from computer vandalism, to fraud, to simple malicious damage, eg the destruction of files, of the issuance of unauthorised cover.

An interesting story here is that of the Insurance company that found gaps in its database appearing at random places and at random times. Eventually they found that an unhappy employee was taking a handful of punched cards out of a basket awaiting input on those odd occasions when she passed it.

Careful procedural planning and recruitment techniques can help avoid such situations, as can motivation and general awareness techniques. 


\section{d) Training}

In addition to the high level of expertise available in the Personnel function, the horizontal approach of the Risk Manager can perhaps identify those areas where management controls are weakest, or the most difficult, and encourage concentration of training in the areas where the need is highest.

Apparent clerical functions such as the filling in of cover notes, or the completion of computer input data can expose a company for large sums of money. Training may be a more effective technique than unrealistic control expectations.

e) Previous convictions, alcohol usage / abuse, biorhythms

These are a mixture of situations where there can often be possible exposures to the company, but no obvious person to co-ordinate the situation.

Specific procedures should exist to help those with problems, both to isolate them from exposing the company's assets, and to use the medical insurance in the most efficient and effective way possible.

Problems can also arise from persons "coming out", or suddenly becoming single parents, or experiencing some other kind of situation which can upset them, or their colleagues.

There even exist organisations that monitor the biorhythms of certain key staff to ensure that important actions or decisions are not taken when certain elements are "low". While doubtless such a practice may arouse scepticism in many, perhaps the studying of such techniques might possibly result in saving very large sums of the firm's money.

f) Medical cover

It is said that in the US, workmens' compensation will be one of the most important topics for Risk Managers for the rest of this century.

Even in the UK many companies are experiencing rising health costs, and consequently increasing expenditure for the firm, and its employees where the scheme is contributory.

The ability of the company to control health costs can have a direct bearing on its ability to control its expenses and consequently its competitiveness and its profitability.

Once again the horizontal approach of the Risk Manager over the spectrum of departments, line management, ergonomics, recruitment, training, and other factors, can help reduce exposures and costs.

One emerging head of exposures is "Occupational Stress", not only causing absence from work, and medical expenses, but also the potential for liability exposures in the US.

Research shows that occupational stress can occur at any level in a company, and the increasingly competitive environment which all companies now have to face will undoubtedly lead to an increased incidence of this problem.

Stress claims are costing California's employers US Dollars 380 million annually... and it is quite clear that many of the legal exposures that arise in the United States eventually find their way to Europe.

The European Economic Community consecrated 1992 as the year of "Safety, Hygiene and Health in the work place", and in a survey, 42 per cent of the salaried workforce of the 12 member states considered that their work affects their health. Stress and back pain were the top listed problems. 
Stuffy, windowless offices, inefficient air conditioning, florescent lighting and unattractive decor can also have a vital influence on staff morale and general attitude.

The consideration of a non-Smoking environment may also be a factor for both medical cost and liability exposures not only in the US, but in Europe as well.

In 1990 a 16 persons panel of independent science advisers to the Environmental Protection Agency (EPA) concluded that second hand cigarette smoking ought to be designated a cause of lung cancer.

This conclusion will doubtless be translated into workplace standards. No risk manager can ignore the fact that smoking related lawsuits are becoming commonplace - the journal of the Institute of Risk Management - February 1994 issue - deals with this topic in its lead article. The potential exposure could outpace that stemming from asbestos.

However these types of problem develop, and ultimately venture across the Atlantic; it is clear that these exposures must be addressed by the risk manager.

Hiring employees under the various disabilities acts is also relevant both for recruitment and medical costs.

While this is clearly not a comprehensive list of factors where costs and exposures to the firm can be saved, it is quite clear that there are many factors under this heading worthy of study, and considerable exposures can be avoided, with a saving in costs.

\section{g) Life cover and pensions}

As in many industries, often those most expert at giving advice to others forget to provide the same level of service to their employees.

There can be some real misunderstandings both as regards the level of contributions and benefits. There has been considerable polemic between "defined benefits" and "defined contributions", and misunderstood definitions have resulted not only in unsatisfied personnel, but even in inadequate financing leading to the bankruptcy of the company.

Exposure to litigation for insufficient cover in a pension fund is also increasing.

\section{h) Travel insurance}

If travel insurance has been considered for key executives, the concentration of executives in one aeroplane, or coach, or car is often left to chance. Equally situations like the "Gulf War" can leave executives or staff exposed or without important insurance benefits in an emergency.

i) Sexual harassment inside and outside the company

It may be difficult to identify certain problem areas within the company, but nevertheless some measure of exposure should be considered.

Outside the company, there could also be exposures, particularly if "attractive" male or female employees are to make inspections or surveys or delicate house calls.

\subsection{Outside the company}

\section{a) Agents / Brokers}

Once again selection / screening methods and parameters can determine whether the outcome of the relationship is a success or failure, eventually involving the company in heavy costs, exposures, and loss of image. 
It was noted that in 1990 former tied agents of a large UK composite were making a claim of Pounds 40 million, suing at first through 30 test cases.

The agents were claiming that the company had failed to process business produced by them, leaving them embarrassed and without commission. The company was disputing the claim.

The qualifications, health and financial situation of Agents / Brokers should be carefully assessed, and the concept of a global agreement should be carefully reviewed against the classes of business involved, the territorial scope of the organisation, and the insurable structures, processes and materials in that area.

Again a HORIZONTAL consideration over the different territories or even countries, coupled with the general and on-going economic situation, inflation and the rise and ebb of certain industries can help to avoid or reduce certain exposures.

The risk manager can set general guidelines for agents / brokers and the on-going review regulations.

Not only are the brokers who will offer business to the company relevant, but also those whom the risk manager may use to transfer risk from the company.

Risk managers are increasingly on the lookout for brokers who can deliver value-added services and function as an extension of their departments.

Certain situations can arise such as fraud, bankruptcy, non-payment, death which fall between departments of functions, but which can nevertheless considerably affect the wellbeing of the firm.

Procedures should exist which deal with exceptional situations with the minimum of interruption, avoiding and/or reducing image or other exposures to the company.

\section{b) Clients} period.

Client quality can also become an area of importance, especially during a recessionary

It is well known that the incidence of fire and crime rises during times of economic difficulty, and there is thus an increased exposure to the insurance company; an exposure which has little connection with the technical aspects of the risk.

Moral hazard is clearly a difficult situation to gauge. Howcver a component in the conclusion is certainly the financial health of the organisation being covered or considered for cover. Some UK Insurance Companies have recently advertised software they use to monitor this exposure.

A financially healthy organisation has usually an interest in its continued and uninterrupted existence. Employees also have an interest in their long term security, and "sweeping up" and other important precautionary operations are likely to be carried out more industriously.

The opposite trend may be detected in a firm that has financial problems, with consequent increase in negligent functioning.

Here again a horizontal view can be taken, and standards can be determined, which ALL clients of the company should reach, before technical considerations arise. The Risk Manager is in a very good position to co-ordinate such policies. 


\section{c) Advisers / Consultants}

Many companies seek legal advice, or accounting and auditing services, or use loss adjusters and other advisers and consultants without being required to review these organisations to certain standards.

Over a number of years connections may become too emotional to maintain objectivity, while many firms in this category can evolve for better or for worse, as partners and others move in and out of a practice, or retire.

Firms can also become out of date, or simply not be moving with the times.

All these aspects should be monitored across the company both to ensure that sound advice is being provided, and the company is getting a competitive edge, and the best image from the use of such contacts.

The charges of such firms are also of significant consequence, and often one or other line or service department may not make enough use of a particular firm or type of firm to justify the research necessary to pick the best at a given price.

It might even be possible that different departments are using the same firm without knowing it, and a cost saving could be negotiated if such use was centralised.

At the same time high costs or bad experiences could be transmitted to a central source, to avoid the same problems in the future, saving expense and potential additional exposures to the company.

Some risk managers and claims managers hire legal auditing firms who review legal bills for unreasonable time spent, duplication and exaggerated costs. It is also possible to require advisers to submit legal cost budgets or to follow strict written guidelines previously prepared by the risk manager.

With the development of disputes, and the difficulty to obtain opinions that give more than a 50/50 indication, it may be of consequence that the advice received and paid for, can respond adequately to its own negligence.

As amounts involved can be very large, the E\&O cover available should at least be checked, as should the security behind it.

\section{d) Directors}

The qualifications and standing of prospective and existing directors can be a very sensitive area to discuss or investigate. Nevertheless standards of appropriateness should be considered, and recruits judged accordingly.

Subsequent desire for $D \& O$ and other covers may require minimum standards at some stage.

e) Trade unions, staff associations

While this is an equally sensitive area, the appropriateness of individuals to represent their members, and to disrupt the organisation, should be the subject of review and discussion.

Equally the assistance of such organisations where they exist, to communicate and promulgate a safety/risk management culture will be essential to its success. 
Another point worthy of mention under this heading is the possible impact of foreign trade union movements, either through the acquisition of, or merger with, a foreign company, or even where such companies already exist in the group - through the development of the European Economic Community.

There are already some trade union movements in Europe who are strong in the insurance sector, and see the lack of such organisations in UK insurance companies as an opportunity for expansion.

\section{Material exposure}

\section{a) Buildings}

This is an obvious area of exposure where the principles of Risk Management apply equally to an industrial plant or an insurance company.

The important point here is that the risk manager must take an aggressive stance to the cover available in the market place for the benefit of the company, even if this might in fact conflict with the company's own perceived sound underwriting practices eg not to write property policies on a "manuscript" "all risks" form.

It is also important for the risk manager to review materials used in buildings occupied, those to be acquired, or those that might be acquired through default. Asbestos or other polluting materials could store up numerous liabilities for the future.

b) Computers

Computers is another area where fire, business interruption, water damage, electrical/ electronic damage, criminal acts and negligence, or simply poor software, can all cause enormous loss.

In addition the security of information, and the ability to recover large areas of data following loss, can affect the ability of the company to compete efficiently, and to review policy coverages after a number of years.

An insurance company can have very special exposures in this area, given the amount of confidential information it can store on individuals in the life area for example.

What would some newspapers give to obtain the life proposal forms of high profile politicians.

\section{c) Office contents}

This can range from fine art collected or received over the years, to expensive presentation equipment, to articles held in custody.

Items should be clearly identified and, if necessary, valued to ensure adequate cover.

The ability to replenish stocks of printed material, and other items that require some lead time, should also be analysed to ensure effective continuation of the business following any interruption. (Certain companies are known to store a copy of all their major forms and letter heads off-site, so that in the event of an emergency, these can be photocopied and used on another location.)

One can also introduce here the importance of ergonomics. 
Ergonomics has become a much more popular subject over the last years as it does appear possible to reduce the number of accidents and claims caused by poor job design in terms of lighting, seating, and the whole work station itself.

There are a number of upper extremity cumulative trauma disorders that can result from repetitive motions - today known under the generic heading of "Repetitive Strain Injury".

The most common is Carpel Tunnel Syndrome, and jobs such as data entry appear to have the highest correlation with an individual experiencing this problem. the US.

Carpel Tunnel Syndrome affects about five cases in 1,000 of the general population in

Back pain is another problem. The cost is in excess of 46.5 million lost work days, worth over Pounds 4.5 billion in the UK.

The fact that companies continue to encourage specialisation and to introduce ever improved higher technology, means that the human body is likely to be further encouraged away from the varied functions of older job descriptions towards repetitive motions.

"Whereas yesterday's secretary filed, took dictation, typed, and answered phone calls, today's administrative assistants are often asked to employ but one or two of their skills word processing, for example, or phone work in the name of efficiency. When the same muscles are asked to do the same work for eight hours every working day, the outcome is predictable." (Risk Insurance - August 1992.)

However equally of note is the fact that simple preventative measures exist, which can reduce noticeable amounts of exposure.

Simple exercises are available which can be done at the work location for only 10 minutes per day, and which help to combat cumulative trauma disorders.

The interest in ergonomics appears justified and worthy of further study, given the potential for risk reduction.

d) Office cars

I'm sure you all know some of the classic sayings about company cars - for example:

- Battery, oil and tyre pressures do not need to be checked.

- The cars can be driven up to 150 miles with the oil warning light flashing.

- They need cleaning less often.

- They are adapted to allow the reverse gear to be engaged whilst the car is moving forwards.

- Unusual and alarming engine noises are easily eliminated by the adjustment of the fitted radio volume control.

- No security is needed, and the car can be left anywhere, unlocked, with the keys in the ignition.

On a more serious note this is a typical area where retention, as opposed to insurance, for the many small losses that arise, can be reviewed, and suitable deductibles and retentions calculated.

In addition to the traditional areas to be investigated, one might suggest a study of which cars are safest, to ensure minimum breakdowns and potential injuries, for example, 
those travelling in big cars are less likely to be injured than those travelling in small cars... and I'm sure many of you would agree that a big company car is much more comfortable than a small company car!

Fleet discounts and the use of a sole supplier can also assist in cost reductions not only at purchase, but also at the time of replacement or repair.

\section{Procedural exposure}

\section{a) Underwriting manual standards}

During the evolution of an insurance company, it often happens that individual line managers devise underwriting manuals for the more efficient operation of their departments.

These tomes are developed over the years in each department, by successive managers, following each persons' idea of underwriting, and the demands of various company policies.

However content, vocabulary, layout and philosophy can often differ greatly between the various manuals in the various departments, and misunderstandings and misinterpretations can arise, as can communication problems between departments who use the same terms to mean different things. For example one department may cede premiums traditionally on a net basis, while another always cedes on a gross basis, thus their notion of premium is different. The same could happen with "PML", and "sum insured" exposures.

By establishing standards of layout, vocabulary and philosophy, one can aid communication, training, and the establishment of a more unified culture, based on sound underwriting and risk management concepts.

\section{b) Underwriting controls}

It has often been said that the "pricing" in Insurance is established fairly low down in the hierarchy, especially for the more homogenous risks.

Nevertheless, even the more common homogenous risks can result in considerable liability devolving upon the company, especially where a manual can easily be mis-read, or a cover note mistakenly issued.

Whilst controls may exist on paper to cover for such situations, it may often be the case that if the manager or supervisor exercised such control effectively, for example, checked carefully each cover note prepared by their staff, they would have no time to complete their own tasks.

Often such checking is done on a sample or cursory basis, and because during the years no problems have arisen, the practice continues, while sums insured and exposures are rising significantly.

To recognise the possibly unrealistic optimism inherent in such situations, it is essential to review all such procedures, and highlight areas of significant exposure, ensuring that the controls and balances of the organisation are thoroughly covering the main areas of exposures.

In addition, regular audits of head offices and branch functions to check the level of conscientiousness will help to encourage and show the success of a good risk prevention culture. 


\section{c) Decision criteria}

It is often unclear at what level decisions should be referred to, or subject to control.

Generally underwriting, investment or personnel decisions are given parameters. Mr. X may not underwrite risks where the sum insured exceeds Pounds $10,000,000$. Mrs. Y may not invest in certain types of Bonds, or certain types of high risk transaction.

However often such parameters are given for different reasons at different levels in the various line departments, and the accumulation and spiral effects, as well as the general exposure levels are not given adequate consideration.

A relatively new underwriter may receive authority to write quite significant lines on certain types of cargo business, while the authorisation of a cheque of a similar sum must go through several levels of control.

The ability of a claims controller to authorise the use of an outside adjuster may require time consuming authorisations, while the potential of loss through delay might be many times greater.

The absence of the next level of authority, for any reason, may cause a crucial delay, where the delegation of more flexibility at times of absence may enhance the company's image or conserve the company's assets.

The establishment of broad parameters over the whole structure, with procedures in the case of absences, can reduce unnecessary delays and exposures, and harness the abilities within the whole structure, where one or other of its individuals may the lacking.

Different elements can also have an influence on decisions at different times.

For example the concept and calculation of underwriting profit could vary quite regularly depending on a number of economic and industry factors. A sudden increase in reinsurance/retrocession costs could also have a marked effect on profitability and hence on the correct original rates to apply. A means to effectively and rapidly communicate such elements to the necessary departments and units could noticeably influence the ultimate results of the company, especially where, for example, end-of-year renewals coincide with the purchase of reinsurance/retrocession cover.

\section{d) Communications}

All employees should be given some indications on the types of information which are invaluable to management in general.

In both company and private life, an employee may come to possess information that could be of real value to the company - without in any way prcjudicing the position of the donor.

This could involve macro-environmental subjects - politics, legal developments, general and specific economic situations; or micro-environmental subjects, such as the latest position on a client, a computer bug, or an unsafe area in the building.

In addition innovative ideas, or comments on flawed policies, may save the company considerable sums, and steps should be taken to ensure that dogma and differentials do not impede or distort these important information flows.

This involves not only the creating and nurture of a good communications culture, but also the establishment of points of information diffusion from senior management, and valuable, publicly proclaimed incentives. 


\section{e) Crisis management}

Most executives will agree that companies should establish a mechanism that will alert them to potential crises and indicate a means to deal with these problems.

It is commonly accepted that most organisations, if they do not experience a major crisis, will not engage in a serious programme of crisis management.

Crises can result from numerous areas:

- Power failure.

- Strike, or other industrial action.

- A major computer crash, or failure.

- Fire.

- Catastrophe.

- Flu epidemic.

- Sexual harassment.

- Kidnapping.

- Death of a key employee.

- Negative media exposure.

- Government intervention.

- An official enquiry - drawn raids - Fraud squad, DTI investigation, Customs and Excise.

- Industrial espionage.

- Consumer terrorism.

- Major fraud.

- Hostile takeover.

- Bomb threat.

- Retroactive lesgislation.

- War - Home or abroad - or threatened - call up of key personnel, ...to name but a few.

The unexpected death of Robert Maxwell, the newspaper tycoon, in 1991, is a good example of a group of companies faced with a media exposure, with the obligation to quickly and effectively respond to the crisis.

The withdrawal by Lucozade of several million bottles from store shelves in 1991 is another example of the need for a company to suddenly react to crisis, in this case a form of consumer terrorism.

By going through a questioning process -

What can happen?

What operations will be affected?

What will be the overall consequences for the company?

What can the organisation do to avoid these effects?

- one can determine the problems in the various types of crises.

Insurance companies can have a particular exposure, especially as regards their own image, and even that as a representative of the Insurance Industry.

As risk specialists, their ability to deal with a given, potentially catastrophic situation, is already assumed by the public at large. Failure to do so can considerably affect their image. 
A disaster recovery plan also helps to stem the cost of a catastrophe. In the age of the mainframe, one can begin to imagine the situation in a large composite with many branches, if a disaster prevented item processing over a large part of their trading operations.

Catastrophes grow exponentially.

A study was made in respect of a California Bank with 300 branches. The catastrophe envisaged was a large earthquake. It was concluded that on day one the bank would loose about 7 million Dollars in revenues. After 10 days the banks losses would reach 480 million Dollars. A plan was devised to resume wire transfers within 24 hours and to restore other critical operations over 72 hours.

An interesting aspect from a London viewpoint might also include the topic of Strikes.

Although a prolonged strike by British Rail would doubtless cause a lot of problems, a prolonged national post strike would also cause potentially disastrous effects on cash flow and working capital due to delayed invoicing and receipts.

Strikes are certainly not likely to disappear in the years up to 2000 , while the increasing interdependence of markets as the European Economic Community evolves, can only make matters potentially more difficult.

In addition the European Social Action Programme appears to have a more liberal attitude than the British System to the right of employees to take strike action.

It is quite clear that many insurance companies would benefit from the input of an experienced risk manager in this area.

f) Claims management

The penetrating remark "We do not need to advertise, we pay claims", underlines the importance of the claims department in an insurance company.

The exposures that can arise from the ill considered choice and use of the wrong outside adjusters and other potential advisers has already been dealt with above, and the role of the risk manager discussed with regard to this aspect.

Nevertheless the procedures adopted in the claims department can also have a significant impact on the company's clients, as on the company's exposures.

For example, at what level and under which circumstances should the company attempt to telephone adjust claims, and/or send out a claims form in the post, and/or ensure an immediate personal contact with the claimant?

Could a kind and helpful voice, rather than an impersonal claims form received several days later, save considerable sums on minor injuries and damage in small motor accidents?

At what level of premium, or claim, or exposure to the company, does a policyholder qualify for special treatment?

At what stage should particular fraud teams, or the police, be called into an investigation? What internal procedures should be applied?

Equally the question of Crisis Management, already discussed above, is most relevant here.

g) Planning

There are many different types and stages of planning carried out in an insurance company. 
Generally the process is a vertical and divisional one. Departments give forecasts of their incomes and costs over a period of time, and their action plans, following a broad picture conceived by the senior management.

As in many of life's situations, there is likely to be some mixture between the ambitions of the company, and the personal ambitions of its more powerful, persuasive or vocal members.

Departmental competition, which can also be quite healthy, can create obstacles to the smooth integration of objectives at different levels.

Management at the highest levels, who have the responsibility to co-ordinate and integrate, can only deal in detail up to a certain time consumption. Yet at any level below this, there will be increasing regionalism of objectives and purpose.

Here again, the risk managers, and their staff, will have HORIZONTAL knowledge of the company at a number of levels, and they can ensure, through the careful setting of parameters and co-ordination controls, that conflicting objectives are minimised, and similar objectives correctly integrated.

For example, the fire department may have an objective to avoid co-insurance and write larger shares on bigger risks. This will give it a leader image in the market place, and hence some strategic advantage. They will support this with an advertising campaign already several months in advance. Nevertheless they intend to write a similar income to the previous year - saving on costs, as the number of risks will reduce significantly.

The reinsurance department on its side, provides objectives very similar to those of the previous year, but notes a definite shrinkage in reinsurance capacity.

It is quite clear under such circumstances, that the company could end up with target exposures much greater than ever before, but less reinsurance cover. If an advertising campaign has also been set in motion, there could be an image problem as well.

With little income variation, and perhaps more important problems in the plan, will such problems be picked out? Who will ensure that the relevant divisions will co-ordinate the problem in the appropriate manner?

While the risk manager may not have the authority at such a level, he or she can at least act as a monitor, and sound the alarm if the company's assets are being exposed beyond the amounts set down by the senior management.

\section{Legal exposures}

There is an ever growing body of legislation which involves considerable additional expense or the personal liability of the directors and officers, particularly in the area of health and safety.

For example the EEC VDU directive stresses that where health and safety laws are concerned, employers are obliged to keep themselves informed of their responsibilities. There are substantial penalties for non-compliance.

The Health and Safety Commission is quoted as saying that industry in general may face costs of Pounds 300 million in the year of implementing a range of new European Community health and safety laws.

Who is best suited in an Insurance Company to review the task it may face? 
Once again there is need for a HORIZONTAL scanning process to identify and coordinate, to report and integrate.

Another typical issue here might be the evolution of laws regarding liability in cases of pollution.

Many companies provide mortgages to staff which could result in environmental exposures.

Where a company has its main office in a small locality, it may be the major employer of the area, and consequently have an accumulation of loans.

Should an area reveal pollution due to previous usage, and later on become a place where a number of employees live, the accumulation of problems resulting could be quite significant.

\section{Image exposures}

The definition of "image", and the definition of "loss" resulting from damage to this "image" are already a source of problems and uncertainty.

In a small town where the company may be an important employer, a public altercation on a Saturday morning in the middle of the town between a person known to be an employee of the company and a third party can potentially affect the image of the company.

Senior executives with unfortunate drinking habits, or forthright opinions, or generally unacceptable religious, or racial, or political views can greatly affect the company's image.

Here the line between "The Company", and the rights of the "Private Individual" must be considered, even where a code of ethics has been established.

The appearance of an office, or even cleanliness of official cars can affect image.

Is this important, does it really matter?

Failure to settle a genuine claim, or a critical court judgement can also affect image.

Any company publication, from a local internal paper intended only for staff, to a nationally or internationally circulated document can affect image.

Speeches, or talks can also have unfortunate consequences, and off-the-cuff remarks in a public forum.

There is certainly considerable reluctance in most organisations to lay down too many rules and regulations, and in most societies we no longer could obtain acceptance to company hair cuts, company uniforms, and "uniform" behaviour.

However the attitude of employees to Image, and even their conception of this "Image" can only exist if the company takes steps to communicate such matters.

Once again, one might suggest that while much input can be obtained from those expert in communications, the identification of the potential sources of exposure might well be usefully given to the risk manager.

\section{Economic and political exposures}

The typical economic exposures would cover such areas as inflation, currency fluctuation, stock markets and other key economic indicators.

Government political actions are however just as difficult to predict. 
The example of the Italian Government's proposed plan to increase taxes on some insurance companies to set up a fund to compensate businesses that fall prey to the Mafia, is quite typical of the wholly unpredictable.

The insurance industry is often viewed as an industry with funds available to solve certain social problems.

Here again there are areas of exposure where all the management of the company can fully support the importance of being kept well informed, but where often few, if any, parameters exist of exactly what information, in what quantities, should be given to whom?

Finally even a competent risk manager will be no superman or superwoman.

But it is clear that with the significant changes occurring in today's insurance and reinsurance markets, the existence of persons able to fulfil such functions, alongside the current management and general management functions, is mostly lacking.

For the study done for the Chartered Insurance Institute, I discuss further the creation of a risk management function in an insurance company, and then deals with a more detailed risk management approach to Information Security, which must today be one of the most exposed areas within an Insurance Company.

There is also a section dealing with the results of a questionnaire sent to a number of risk managers worldwide, asking them what they thought of the idea.

Before concluding this paper, I would like to flash back to the time when I first came across the idea of "Risk Management for Insurance Companies".

The coining of the phrase originated for me in a paper prepared by Pierre-Claude Perrenoud, then a manager of one of the Regional Departments at Swiss Reinsurance Company.

One of the essential elements was to encourage dialogue between Reinsurers and their major clients - Insurance Companies.

My enthusiasm in those days led me to believe that reinsurers might be able to extend the range of their services to include a Risk Management Service for Insurance Companies.

Those older and wiser than me pointed out that it might be better for reinsurers to get their own house in order before they offer risk management advice to others!

I am sad to note that to many, Risk Management appears as a wholly different discipline to that of Insurance.

It seems to me that there should be much more overlapping between the two concepts, and that Insurance entities need to expand their product range and their risk services if they are to fulfil the increasing demands of their clients in an ever more complex world.

Incorporating risk management techniques into their own management systems seems to be a good way to promote this development in addition to all the other benefits set out in this paper.

Finally, I would like to acknowledge here all the ideas gleaned from books and articles which have made this paper possible, and also thank many in insurance and risk management, who through friendly, and not so friendly discussions, keep Risk Management developments so very alive. 